\title{
MATHEMATICAL PHYSICS ELECTRONIC JOURNAL
}

Print Version 
This page is intentionally left blank 


\section{MATHEMATICAL PHYSICS \\ ELECTRONIC JOURNAL}

Print Version

Volume 5, 1999

Chief Editors

J.-P. Eckmann

G. Gallavotti

H. Koch
Volume 6, 2000

Chief Editors

P. Collet

H. Koch

C. E. Wayne

Technical Editors

R. de la Llave

H. Koch

\section{Radin}

Department of Mathematics University of Texas at Austin USA 


\section{Published by}

World Scientific Publishing Co. Pte. Ltd.

P O Box 128, Farrer Road, Singapore 912805

USA office: Suite 1B, 1060 Main Street, River Edge, NJ 07661

UK office: 57 Shelton Street, Covent Garden, London WC2H 9HE

\section{British Library Cataloguing-in-Publication Data}

A catalogue record for this book is available from the British Library.

\section{Mathematical Physics electronic JOURNAL \\ Volumes 5 and 6 (Print Version)}

Copyright $\odot 2002$ by World Scientific Publishing Co. Pte. Ltd.

The copyright of each article is owned by the author(s).

All rights reserved. This book, or parts thereof, may not be reproduced in any form or by any means, electronic or mechanical, including photocopying, recording or any information storage and retrieval system now known or to be invented, without written permission from the Publisher.

For photocopying of material in this volume, please pay a copying fee through the Copyright Clearance Center, Inc., 222 Rosewood Drive, Danvers, MA 01923, USA. In this case permission to photocopy is not required from the publisher.

ISBN $981-02-4881-4(\mathrm{pbk})$

Printed in Singapore. 


\section{Preface}

The main goal in the creation of MPEJ was to have a journal that was distributed as widely as possible in the community and that had as its only criterion for acceptance the quality of the papers. In particular, we did not want that considerations of the number of pages to be published every year entered into decisions of acceptance.

These goals are well served by the free electronic distribution of the papers and the electronic supplements available from:

- http://www.ma.utexas.edu/mpej

- http://mpej .unige.ch/mpej

- http://www.maia.ub.es/mpej

and the about 20 mirrors organized by the European Mathematical Information Service (EMIS) whose main server is:

- http://www . emis.de

We think that adding a print version of the papers to the electronic distribution will increase the availability and, given that there is no commitment of pages nor any financial incentive for editors or authors, it will allow MPEJ to keep quality as the sole criterion.

We thank World Scientific and, specially Dr. Sen $\mathrm{Hu}$ for the organization of this print version. 


\section{MPEJ}

Mathematical Physics Electronic JournaL*

ISSN 1086-6655

\section{Volume 6, 2000}

\section{Chief Editors}

P. Collet
Ecole Polytechnique
Palaiseau

J.E. Avron

Israel Institute of Technology

Haifa

J.-P. Eckmann

Université de Genève

Geneva

R. Kotecký
Charles University
Prague

H. Spohn

Universität München

Munich
H. Koch

The University of Texas

Austin

\section{Editorial Board}

G. Benettin

Università di Padova

Padua

J. Feldman

University of British Columbia

Vancouver

A. Kupiainen
Helsinki University
Helsinki

R. de la Llave

The University of Texas

Austin

C.E. Wayne
Boston University
Boston

P. Constantin

The University of Chicago

Chicago

G. Gallavotti

Università di Roma La Sapienza

Rome

H. Tasaki

Gakushin University

Tokyo

* For an electronic version of this volume, and for information on subscriptions and other matters, see http://ww.ma.utexas.edu/mpej/ or http://mpej.unige.ch/mpej/ or http://ww.maia.ub.es/mpej/ or send an empty e-mail message to mpej@maia.ub.es for instructions. 
This page is intentionally left blank 


\section{MIPE]}

Mathematical Physics Electronic Journal*

ISSN 1086-6655

\section{Volume 5, 1999}

\section{Chief Editors}

\begin{abstract}
J.-P. Eckmann
Université de Genève

Geneva
\end{abstract}

J.E. Avron
Israel Institute of Technology
Haifa

P. Constantin

The University of Chicago

Chicago
A. Kupiainen
Helsinki University
Helsinki
H. Tasaki
Gakushin University
Tokyo

\author{
G. Gallavotti \\ Università di Roma La Sapienza \\ Rome
}

\section{Editorial Board}

\author{
G. Benettin \\ Università di Padova \\ Padua
}
J. Feldman
University of British Columbia
Vancouver

R. de la Llave

The University of Texas

Austin

\section{P. Collet \\ Ecole Polytechnique \\ Palaiseau}

\section{R. Kotecký}

Charles University

Prague

H. Spohn

Universität München Munich
C.E. Wayne

Boston University

Boston

* For an electronic version of this volume, and for information on subscriptions and other matters, see http://ww.ma.utexas . edu/mpej/ or http://mpej.unige.ch/mpej/ or send an empty e-mail message to mpej@math.utexas.edu for instructions. 
This page is intentionally left blank 


\section{Contents \\ Volume 5 (1999)}

I. Guarneri Lower Bounds on Wave Packet Propagation

H. Schulz-Baldes by Packing Dimensions of Spectral Measures

G.D. Raikov Eigenvalue Asymptotics for the Dirac Operator in Strong Constant Magnetic Fields

S. De Bièvre Propagating Edge States for a Magnetic

J.V. Pulé Hamiltonian

F. Bonetto On a Conjecture for the Critical Behaviour

G. Gentile of KAM Tori

Y. Lacroix Local Perturbations of Energy and Kac's

65 Return Time Theorem

G. Hoever Stability of the Brown-Ravenhall Operator

H. Siedentop 
This page is intentionally left blank 


\title{
Contents \\ Volume 6 (2000)
}

\author{
M. Salmhofer Construction of the Renormalized $\mathrm{GN}_{2-\epsilon}$ \\ Chr. Wieczerkowski Trajectory \\ E. Valdinoci Families of Whiskered Tori for a priori \\ Stable/Unstable Hamiltonian Systems and \\ Construction of Unstable Orbits
}
A. Schenkel Computer-Assisted Proofs for Fixed Point
J. Wehr Problems in Sobolev Spaces
P. Wittwer

K. Borchsenius Degenerate Space-Time Paths and the Non-

Locality of Quantum Mechanics in a Clifford Substructure of Space-Time

B.D. Mestel Periodic Orbits of Renormalisation for the

A.H. Osbaldestin Correlations of Strange Nonchaotic Attractors

L. Bowen Circle Packing in the Hyperbolic Plane 